\title{
Static and Dynamic Analysis of Aircraft Wing Made by LM 25 and ALSiC Metal Matrix Composite
}

\author{
G. Yeshwanth, K. Srinivasulu Reddy
}

\begin{abstract}
This paper discusses about the weight reduction in the wing structure that improves the productivity and performance of an aircraft wing. Decrease in the mass of the wings has higher significance compared all other air craft parts Aircraft wing structures are analyzed with LM25 and a metal matrix composite material which is a mix of LM25 and Silicon Carbide (SiC) where in aluminum is the base metal and silicon carbide is added in different weight proportions. By varying silicon carbide percentage in LM25 four types of samples are prepared utilizing stir casting process. The young's modulus, Poisson's ratio and thickness of every sample are determined cautiously by exposing the sample to tensile test and hardness test. By looking at the material properties acquired tentatively ideal level of silicon carbide in aluminum is found. Static basic investigation is completed in ANSYS by contributing the properties of the ideal example which are acquired tentatively. The outcomes acquired from ANSYS for pure AL25 and metal matrix composite (SiC) are compared. By looking at the outcomes it is discovered that composite material has preferred material properties and stresses over LM25.
\end{abstract}

Keywords: Aircraft wing, Aluminum alloy (LM25), Silicon Carbide (SiC), stir casting.

\section{INTRODUCTION}

The design and manufacture of aircraft wings require attention to several unique structural demands. High strength and light weight are the two primary functional requirements to be considered in selecting materials for the construction of aircraft wing. Traditionally aero planes have been made out of metal like alloys of aluminium. Now a days the silicon carbide metal matrix composites have replaced the traditional metals, to make an aircraft lighter with added benefits of less maintenance, super fatigue resistance and high fuel efficiency. These composite materials can provide a much higher strength to weight ratio and stiffness-to-weight ratio than metals. In order to study the structural behaviour of a wing the linear static analysis is carried out on an aircraft wing and the stresses and displacements are analysed. The objective of this study includes structural idealization, Finite element modelling using ANSYS.

Aircrafts performance augments by reducing its weight as much as possible. So, the materials used in manufacturing the aircraft should be light in weight and strong to withstand the massive amount of force experienced in the sky. Hence Aluminum is the optimum qualities when mixed with silicon carbide in very accurate proportions. For this we need to study the material properties of aluminum and silicon carbide by casting some sample test specimens and simulating them with different testing methods in lab like hardness, tensile, and compression tests. And optimum mixing of both the materials is also found for finding optimum mixing ratios. Considering the alloy that is to be used its properties like Poisson's ratio, density and other materialistic properties are noted down and they are now inculcated into CAD software for simulation. Frist the wing structure is designed using CATIA V5R20 software and it is exported as IGES file to import in to ANSYS 18.5 simulation software for simulating the model with ultimate loads that an aircraft experiences in the atmosphere and final outputs like Maximum principle stress, maximum shear stress, maximum deformation of the structure is monitored.

\section{MATERIALS AND METHODS}

For the preparation of metal matrix composites, aluminum mixture (LM 25) is utilized as base material, silicon carbide in powder structure are utilized as the support. Silicon carbide having cross section size $(30 \mu \mathrm{m})$ aluminium alloy slab is cut into small pieces of $1 \mathrm{~kg}$, so that it can be easily placed in graphite container for melting.

Properties of LM25 alloy are presented in table 1

\begin{tabular}{|l|l|}
\hline PROPERTY & Values \\
\hline Density & $2700 \mathrm{~kg} / \mathrm{cm} 3$ \\
\hline Young's modulus & $68.3 \mathrm{GPa}$ \\
\hline Poisson' ratio & 0.34 \\
\hline Tensile strength & $150 \mathrm{Mpa}$ \\
\hline Hardness & $65(\mathrm{HV} 10)$ \\
\hline
\end{tabular}

Table- I: Properties of Aluminum LM 25

ALSiC metal matrix composite is fabricated by Stir casting process as shown in fig.1. In this process the base metal is first melt down and then continuously stirred at the speed of $600 \mathrm{rpm}$ by introducing the silicon carbide pieces in to the molten metal after that they are poured in to the die and allowed to cool down and harden. 


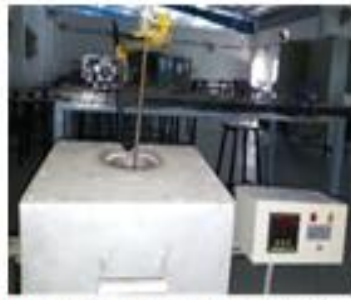

Fig. 1. Stir casting equipment.

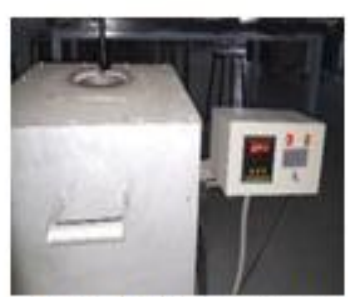

Fig. 2. Temperature setting.
Test specimens are shown in figure 3.

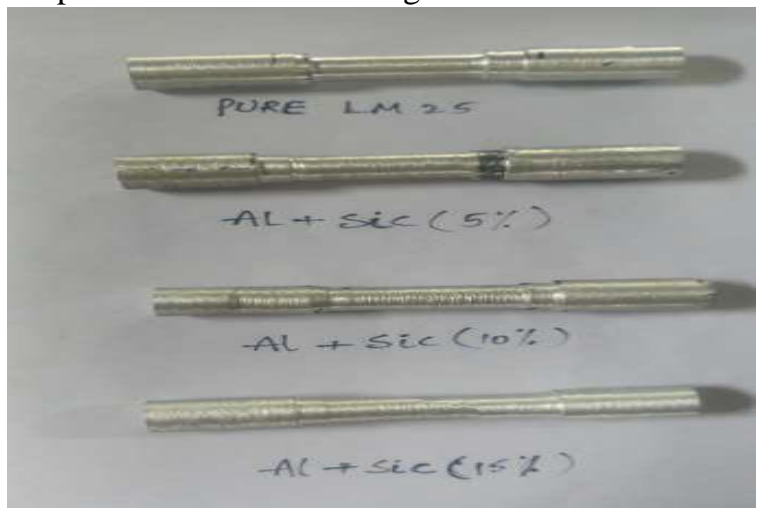

Fig. 3. Test specimens of ALSiC

\section{Mechanical Properties:}

Various mechanical tests are conducted on AlSiC specimens which are fabricated at $5 \%, 10 \%$ and $15 \% \mathrm{SiC}$ to find the optimum percentage of $\mathrm{SiC}$.

Tensile Test:

Tensile strength of the specimens as per ASTM E8 standards is determined using Universal testing machine of $100 \mathrm{KN}$ at room temperature. Strain rate of $2 \mathrm{~mm} / \mathrm{min}$ at room temperature are conducted. Specimens for tensile test were prepared using lathe machine with ASTM E8 standard dimensions.

Tensile strength $=\mathrm{F} / \mathrm{A}(\mathrm{N} / \mathrm{mm} 2)$

\section{Where $\mathrm{F}=$ Force $(\mathrm{N})$}

$\mathrm{A}=$ cross sectional area of the specimen $(\mathrm{mm} 2)$.

\section{Hardness}

Vickers hardness studies were done for the experiment materials utilizing Vickers hardness tester (Hardness tester) with the load of $10 \mathrm{~kg}$ as per ASTM E10 standards. The time of indentation for hardness measurement was 15 seconds. On an average four reading were taken into consideration. This Hardness test is done under ASTM E10 principles. Various other mechanical properties of LM25 and $\mathrm{AlSiC}$ with $15 \% \mathrm{SiC}$ are shown in table 2.

Table 2. Various mechanical properties of LM25 and AlSiC (15\% SiC)

\begin{tabular}{|c|c|c|}
\hline $\begin{array}{c}\text { PROPERTI } \\
\text { ES }\end{array}$ & LM 25 & AlSiC (15\% SiC) \\
\hline Density & $2700 \mathrm{~kg} / \mathrm{cm} 3$ & $2770 \mathrm{~kg} / \mathrm{cm} 3$ \\
\hline $\begin{array}{c}\text { Young's } \\
\text { modulus }\end{array}$ & $68.3 \mathrm{Gpa}$ & $71 \mathrm{Gpa}$ \\
\hline $\begin{array}{c}\text { Poisson' } \\
\text { ratio }\end{array}$ & 0.34 & 0.33 \\
\hline $\begin{array}{c}\text { Tensile } \\
\text { strength }\end{array}$ & $150 \mathrm{Mpa}$ & $55.8 \mathrm{Mpa}$ \\
\hline Hardness & $65(\mathrm{HV} 10)$ & $50(\mathrm{HV} 10)$ \\
\hline
\end{tabular}

\section{Static and Dynamic Analysis of Aircraft Wing}

In this paper it is proposed to compare the Static and Dynamic analysis of aircraft wing made by LM25 and AL10SiC alloy for wing Skelton structure NACA 2412 coordinates are taken for reference and applied the boundary conditions on top of the wing. Material specifications in CATIA is shown in figure 4.
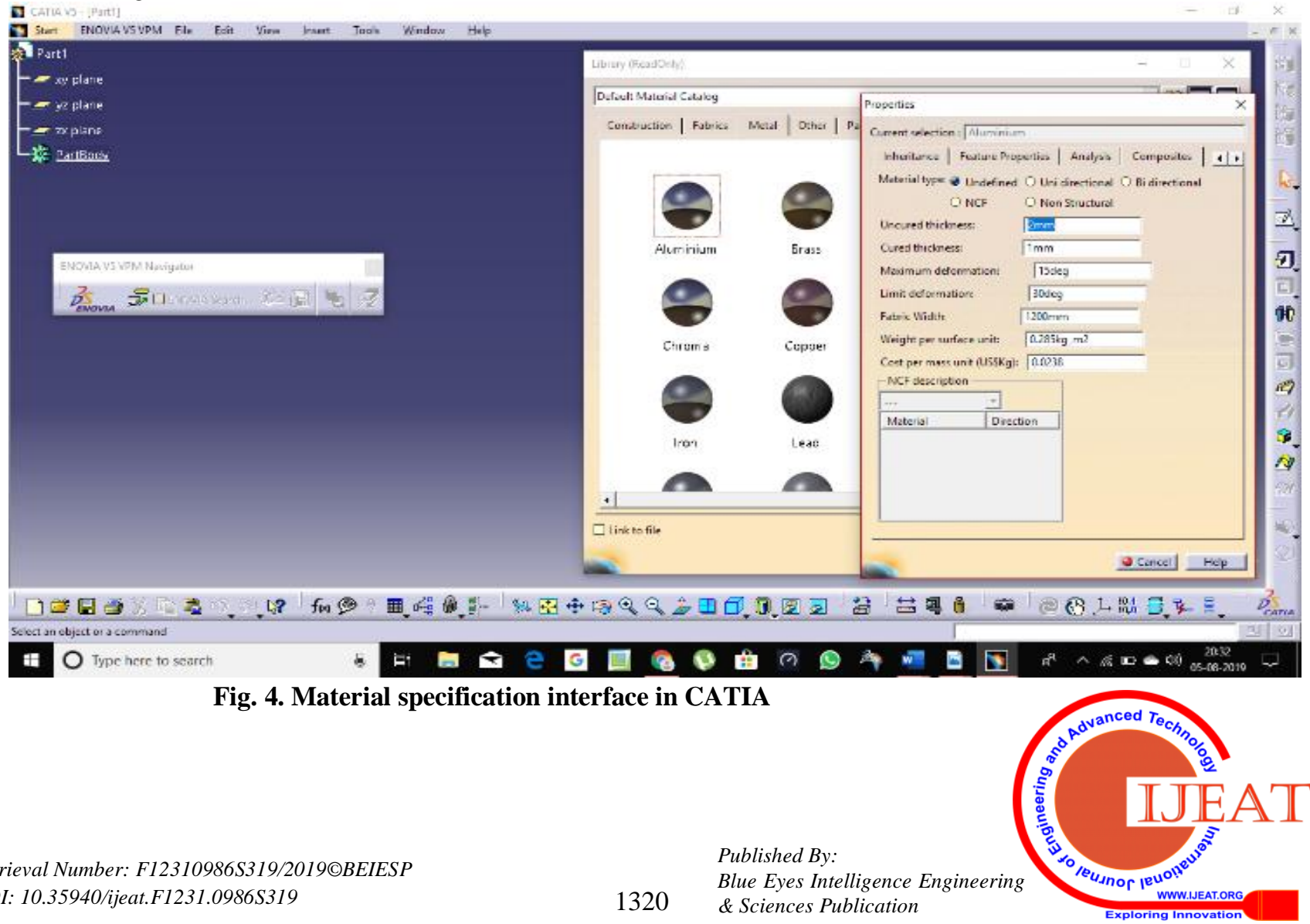
In Fig. 4 we can find that CATIA provides an interface for and customize its properties if needed this helps in easy material specification where we can select the exact type material specification of our simulation model.

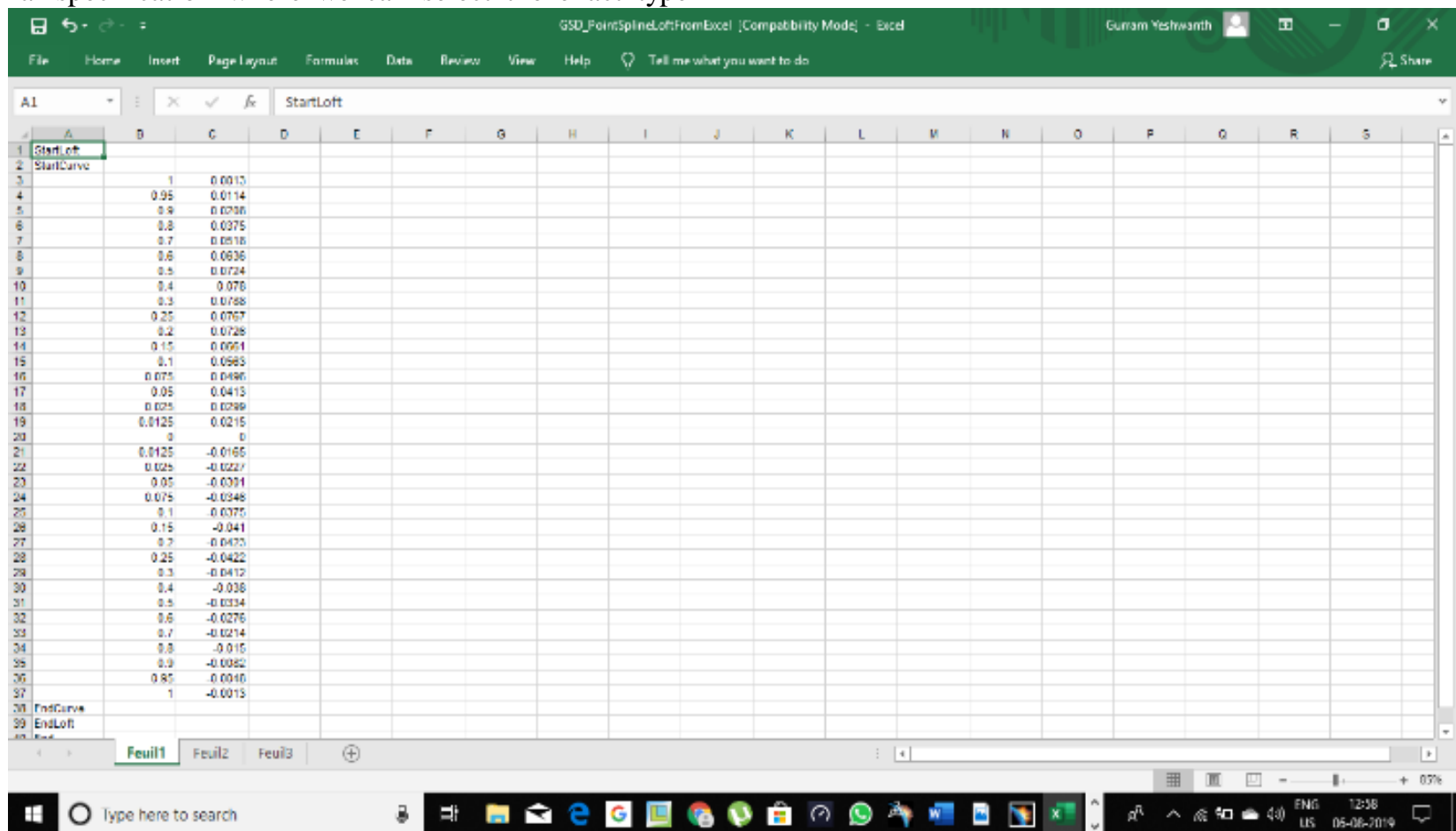

Fig. 5. NACA 2412 Coordinates in CATIA model generation sheet.

We can find in Fig.5 an excel format sheet where we can load the boundary conditions of the models like Air foil, it generates the shape when we run the macros.

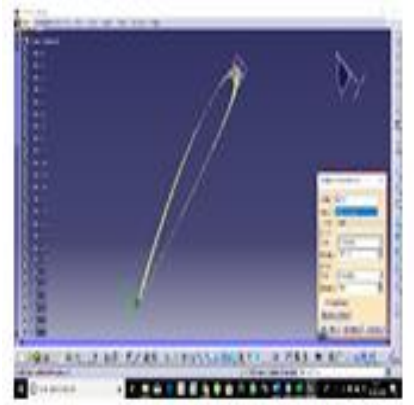

Fig, 6. Airfoil generation.

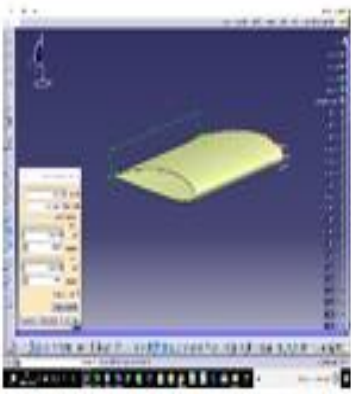

Fig, 7. CATIA wing model.
In Fig. 6 and 7 the generated and extruded models of aircraft wing are displayed this generated model is being imported to Ansys workbench by exporting it as IGES file format.

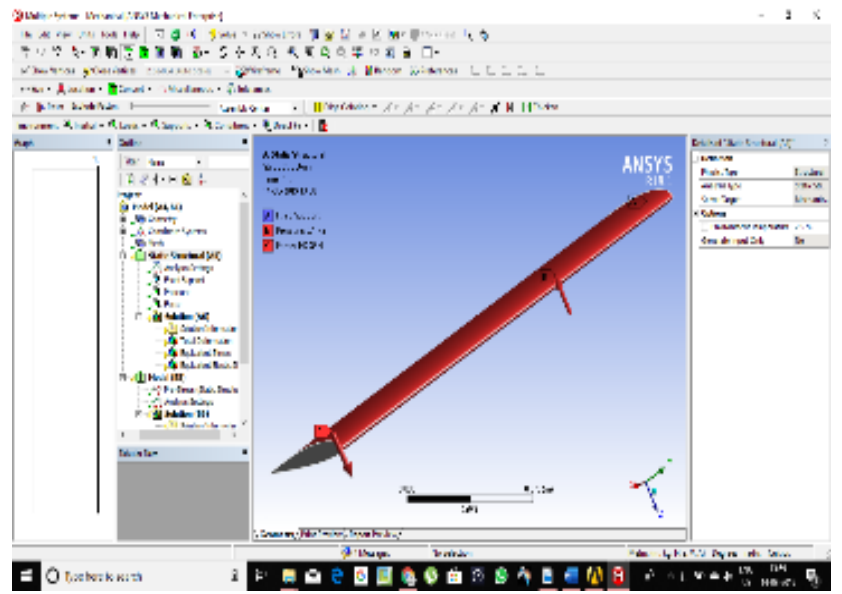

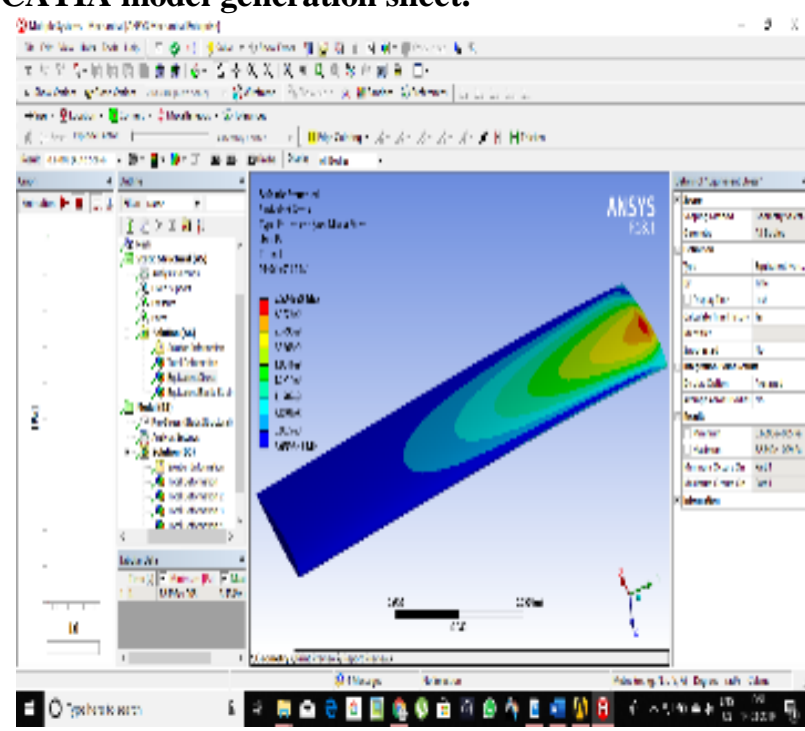

Fig. 8. Applying of force and pressure Fig. 9. Maximum Equivalent stress

Published By:

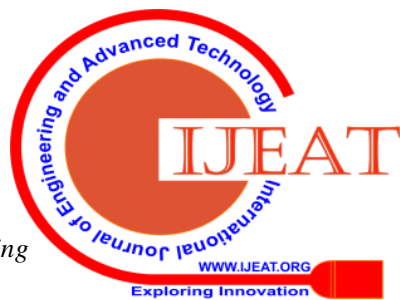




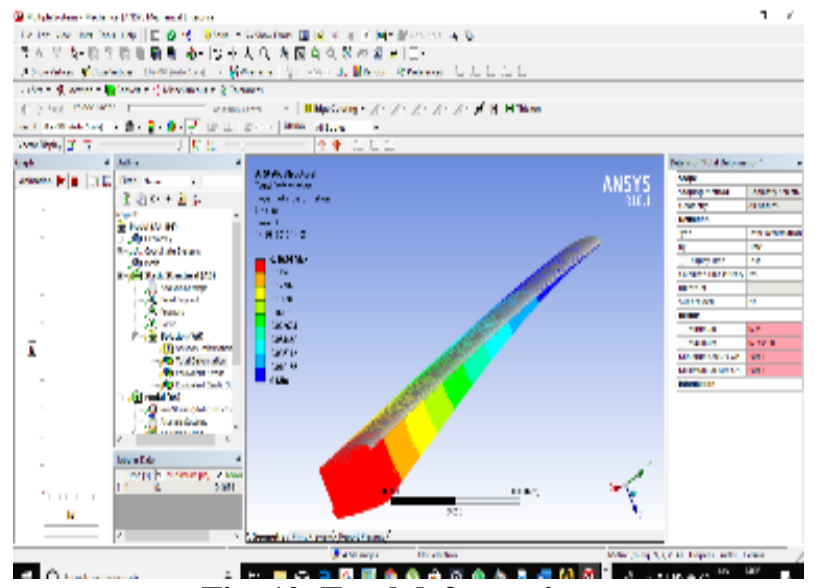

Fig. 10. Total deformation

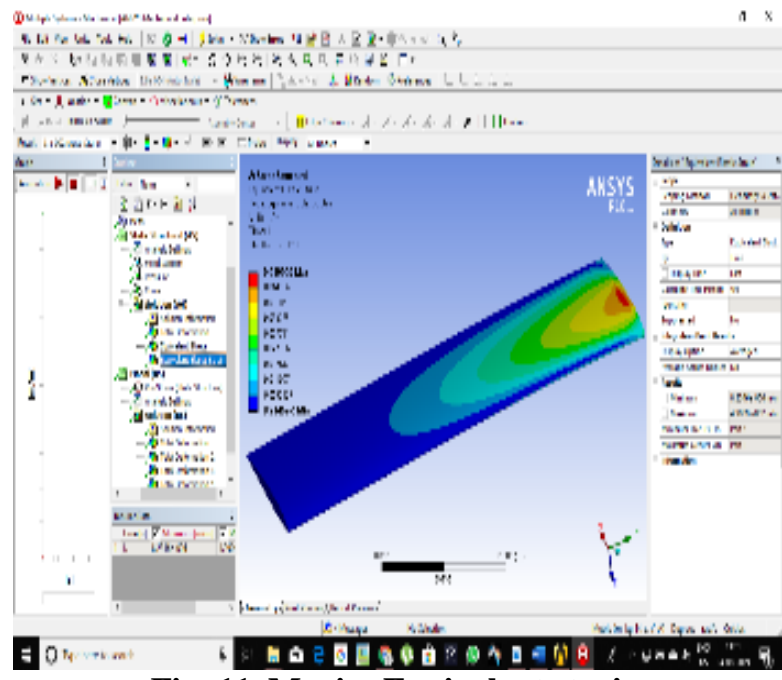

Fig. 11. Maxim Equivalent strain

\begin{tabular}{|l|l|}
\hline Property & Values with units \\
\hline TOTAL DEFORMATION & $0.008112 \mathrm{M}$ \\
\hline EQUIVALENT STRESS & $4.9898 \mathrm{e} 6 \mathrm{~Pa}$ \\
\hline MAXIMUM SHEAR STRESS & $2.7419 \mathrm{E} 6 \mathrm{~Pa}$ \\
\hline SHEAR STRESS & $2.102 \mathrm{e} 6 \mathrm{~K}$ \\
\hline SHEAR INTENSITY & $5.4838 \mathrm{e} 6 \mathrm{~Pa}$ \\
\hline
\end{tabular}

Table-3: Stress Results for AL+15\% SiC

In fig. 8 to Fig. 10 we can find the results of the simulation here applying loads to the model is shown in Fig.8, maximum equivalent stress, Total deformation and Maximum equivalent strain are displayed in remaining figures.

Simulation in Ansys Workbench 18.1 by fixing the wing at one end and applying pressure in the lower part of the wing have shown the results such as Total deformation, maximum equivalent stress, maximum equivalent strain in the wing for the applied load of $2000 \mathrm{KN}$. By comparing the results, we can conclude that ALSiC composite is highly durable, stronger and lighter in weight. Simulation process is done in Many iterations with different types of approach in varying loads and at different pressure points for optimum results.
ALSiC(15\%) STATIC STRUCTURAL

\begin{tabular}{|l|l|l|l|}
\hline Type & $\begin{array}{c}\text { Total } \\
\text { Deformati } \\
\text { on }\end{array}$ & $\begin{array}{c}\text { Equivalent } \\
\text { Elastic Strain }\end{array}$ & $\begin{array}{c}\text { Equivalent } \\
\text { (von-Mises) } \\
\text { Stress }\end{array}$ \\
\hline Minimum & $\mathbf{0 .} \mathrm{m}$ & $\begin{array}{c}8.2346 \mathrm{e}- \\
006 \mathrm{~m} / \mathrm{m}\end{array}$ & $\begin{array}{c}5.6593 \mathrm{e}+005 \\
\mathrm{~Pa}\end{array}$ \\
\hline Maximum & $\mathbf{m}$ & $\begin{array}{c}\mathbf{4 . 9 9 0 9 \mathrm { e } -} \\
\mathbf{0 0 0 2} \mathrm{m} / \mathrm{m}\end{array}$ & $\begin{array}{c}3.5349 \mathrm{e}+009 \\
\mathrm{~Pa}\end{array}$ \\
\hline
\end{tabular}

Table-4 Results for static analysis of ALSiC wing.

\section{LM 25 STATIC STRUCTURAL}

\begin{tabular}{|l|l|l|l|}
\hline \multirow{2}{*}{ Type } & $\begin{array}{l}\text { Total } \\
\text { Deformation }\end{array}$ & $\begin{array}{l}\text { Equivalent } \\
\text { Elastic Strain }\end{array}$ & $\begin{array}{l}\text { Equivalent } \\
\text { (von-Mises) Stress }\end{array}$ \\
\hline Minimum & $0 . \mathrm{m}$ & $8.235 \mathrm{e}-006 \mathrm{~m} / \mathrm{m}$ & $5.6599 \mathrm{e}+005 \mathrm{~Pa}$ \\
\hline & & & \\
Maximum & $0.1985 \mathrm{~m}$ & $5.9910 \mathrm{e}-002 \mathrm{~mm} / 4.5459 \mathrm{e}+009 \mathrm{~Pa}$ \\
\hline
\end{tabular}

Table-5 Results for static structural analysis of LM 25 wing.

ALSiC(15\%) DYNAMIC

\begin{tabular}{|l|l|l|l|}
\hline & $\begin{array}{l}\text { Total } \\
\text { Type }\end{array}$ & $\begin{array}{l}\text { Equivalent } \\
\text { Elastic } \\
\text { Strain }\end{array}$ & $\begin{array}{l}\text { Equivalent } \\
\text { (von-Mises) } \\
\text { Stress }\end{array}$ \\
\hline & & $\begin{array}{l}8.2346 \mathrm{e}- \\
006 \mathrm{~m} / \mathrm{m}\end{array}$ & $\begin{array}{l}5.6593 \mathrm{e}+005 \\
\mathrm{~Pa}\end{array}$ \\
\hline Minimum & $0 . \mathrm{m}$ & $\begin{array}{l}4.9909 \mathrm{e}- \\
002 \mathrm{~m} / \mathrm{m}\end{array}$ & $\begin{array}{l}3.5349 \mathrm{e}+009 \\
\mathrm{~Pa}\end{array}$ \\
\hline
\end{tabular}

Table-6 Results for Dynamic analysis of ALSiC wing.

LM 25 DYNAMIC

\begin{tabular}{|l|l|l|l|}
\hline & $\begin{array}{l}\text { Total } \\
\text { Type }\end{array}$ & $\begin{array}{l}\text { Equivalent } \\
\text { Elastic } \\
\text { Strain }\end{array}$ & $\begin{array}{l}\text { Equivalent } \\
\text { (von-Mises) } \\
\text { Stress }\end{array}$ \\
\hline & & $\begin{array}{l}9.4852 \mathrm{e}- \\
006 \mathrm{~m} / \mathrm{m}\end{array}$ & $\begin{array}{l}6.2543 \mathrm{e}+005 \\
\mathrm{~Pa}\end{array}$ \\
\hline Minimum & $0 . \mathrm{m}$ & $6.2542 \mathrm{e}-$ & $5.3268 \mathrm{e}+009$ \\
Maximum & $1.2658 \mathrm{~m}$ & $002 \mathrm{~m} / \mathrm{m}$ & $\mathrm{Pa}$ \\
\hline
\end{tabular}

Table-7 Results for Dynamic analysis of LM25 wing.

\section{RESULTS AND DISCUSSION}

\begin{tabular}{|l|l|}
\hline Property & Values with units \\
\hline TOTAL DEFORMATION & $0.0001002 \mathrm{M}$ \\
\hline EQUIVALENT STRESS & $4.16956 \mathrm{e} \mathrm{Pa}$ \\
\hline $\begin{array}{l}\text { MAXIMUM SHEAR } \\
\text { STRESS }\end{array}$ & $2.2811 \mathrm{e} 6 \mathrm{~Pa}$ \\
\hline STRESS INTENSITY & $4.5621 \mathrm{e} 6 \mathrm{~K}$ \\
\hline SHEAR STRESS & $1.6588 \mathrm{e} 6 \mathrm{~Pa}$ \\
\hline
\end{tabular}

Table-8 Stress Results for Aluminum alloy (LM25)

From the above tables we can conclude that Aluminum silicon carbide exhibits better material properties than Aluminum alloy (LM25) and is also light in weight and very reliable. From the above experiment we found that composite materials like ALSiC can provide higher strength with lower weight. This property of a material will improve performance of the reliability and performance of the

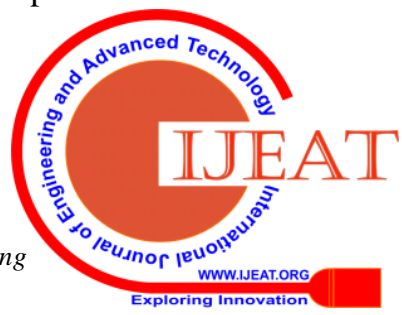


vehicle and decreases the fuel consumption. This type of optimizations is very much required in present day situations where natural resources like crude oil are depleting day by day and is and very important concern to save our natural resources for future generations. ALSiC can be further optimized in future by taking basic principles from papers like this which make research furthermore easier.

\section{CONCLUSION}

From the above CATIA and ANSYS analysis results we can accomplish that ALSiC and aluminum alloys exhibits excellent material properties and is very strong in nature that can withstand maximum force that is experienced by an Aircraft wing by comparison of all the simulation results we can conclude that Aluminum silicon carbide $15 \%$ exhibits outstanding material properties and is very lighter in weight than Aluminum alloy so we can replace Aluminum alloy with Aluminum silicon carbide in Aircraft wing for optimizing its performance and reducing fuel costs.

\section{REFERENCES}

1. P.B.Pawara,Abhay A Utpat, " Analysis of Composite Material aircraft wing under Static Loading Condition" Elsevier(2014)

2. Eng.bogdancaloian, Eng.Dorinlozici and eng.Radubisca, 2009"Stress and Modal Analysis Report for Avert Program”, DOI10.13111/2066-8201.

3. Mr. Mayurkymarkevadiya, 2013“"CFD Analysis of Pressure Coefficient for NACA 4412".

4. Md. Shamim Mahmud, 2013 "Analysis of effectiveness an airfoil with BicamberSurface",ISSN 2049-3444, Vol 3, No 5 .

5. Dr.R.Rajappan, V.Pugazhenthi,2013"Finite element analysis of aircraft wing using composite structure",IJES, Vol 2, issue2.

6. N R PRABHU SWAMY, $\mathrm{C} S$ RAMESH and $\mathrm{T}$ CHANDRASHEKAR ,2010 "Effect of heat treatment on strength and abrasivewear behavior of Al6061-SiCp composites"

7. J.D.Anderson Jr. (2007) "Introduction to Flight", fifth ion, The McGraw-Hill companies.

8. Dr.JanRoskam and Dr.Chuan-Tau, (1997), „Airplane Aerodynamics and Performance.

9. Xi P, Zhang BY, Ning T. Intelligent product design based on open knowledge representation. Acta Aeronautic et AstronauticSinica 2012;33(9):1746-54 Chinese.

10. Anemaat WA, Schueler KL. Airplane layout design using object-oriented methods. 1997. Report No.: AIAA1997-5510.

11. Feng HC, Luo MQ, Liu H, Wu Z. A knowledge-based and extensible aircraft conceptual design environment. Chin J Aeronaut2011;24(6):709-19.

12. La Rocca G, van ToorenMJL.Knowledge-based engineering approach to support aircraft multidisciplinary design and optimization Aircraft 2009;46(6).

13. NACA 4412 airfoil coordinates.

14. Aeronautical textbook by Raymer. 